Article

\title{
An Analysis of the Factors Influencing the Sustainable Use Intention of Urban Shared Bicycles in China
}

\author{
Peng Shao *(i) and Jie Liang \\ School of Management, Xi'an Polytechnic University, Xi'an 710048, China; liangjie@xpu.edu.cn \\ * Correspondence: shaopengde@sohu.com; Tel.: +86-137-0914-2830
}

Received: 5 April 2019; Accepted: 6 May 2019; Published: 14 May 2019

check for updates

\begin{abstract}
Bicycle sharing services have played an active role in building a green travel system in China, but this trend has also caused problems, such as users arbitrarily stopping on the roads or the destruction of shared bicycles. Based on data collected by means of a survey that we designed, a regression analysis is used to test the influence of use perception and consumer characteristics on the intention to sustainably use shared bicycles by measuring the intention to: continue using the service, park the bicycles in an orderly manner, and care and protect the bicycles. We find that: (1) perceived usefulness, perceived ease of use, consumer innovation, and standardized use behavior have a significantly positive impact on the intention to continue using and park shared bicycles in an orderly manner; (2) perceived usefulness, perceived ease of use, and consumer innovation also have a significantly positive impact on the intention to care and protect shared bicycles; and, (3) standardized use behavior has no significant impact on the intention to care and protect shared bicycles. Moreover, urban air quality plays a positive regulatory role in the relationship of perceived usefulness, perceived ease of use, and consumer innovation with the intention to sustainably use the service.
\end{abstract}

Keywords: shared bicycle; sustainable use intention; consumer innovation; air quality

\section{Introduction}

China is suffering from the severe negative consequences of high private vehicle usage in its large and densely populated cities [1]. With the rapid development of information technology and mobile internet, a number of innovative business models that are based on the sharing economy have emerged. The sharing economy is based on the use of means of production and living resources rather than ownership. The combination of the sharing economy concept and public transportation has resulted in the introduction of shared transport services. In recent years, interest has significantly increased in the implementation of vehicle sharing systems, as evidenced by the growth in the number of bicycle and electric car rental programs that can be found throughout the world [2]. Moreover, more than 400 cities worldwide operate bike sharing programs, including in North and South America, Europe, and Asia [3]. In China, shared bicycles, shared cars, and online appointment vehicles are currently the most widely used, the most frequently used, and offer the largest number of shared public transport options. Bicycle sharing systems are public or private systems that are designed to increase the use of bicycles and decrease congestion, solve the last mile problem, and provide a mobility service to users when other means of transportation are not available [3].

The innovative mobility solution that is provided by bicycle sharing, which is now present in most Chinese cities, has made it easier for residents to move around, which relieves pressure on public transportation [1]. The sharing economy is said to be built on the concept of collaborative consumption, a practice that has become increasingly popular in recent years [4,5]. A shared bicycle refers to the short leasing of bicycles from one stop station to another, and it usually refers to time-sharing bicycle leasing with pile-free parking and GPS positioning. The principle of bicycle sharing is simple: individuals use 
bicycles on an "as-needed" basis, without the costs and responsibilities of bicycle ownership. The rapid development of shared-bicycle services in China has played an active role in better addressing public travel needs, alleviating urban traffic congestion, and building a greener travel system. On 25 December 2018, iiMedia Research, which is a leading global economic data mining and analysis organization, authoritatively released the 2018 Chinese Bike Sharing Development Status Research. The scale of bike sharing users in China has reached 0.235 billion people in 2018, as the data of iiMedia Research showed. This figure has gradually stabilized, following a period of rapid growth. Shared bikes are mainly used to meet users' short-distance commuting needs. As the data of iiMedia Research showed, $36.8 \%$ of the interviewed users use shared bikes for commuting purposes. However, the rapid development of shared-bicycle services has also caused problems, such as users randomly parking their bicycles on the street and/or the destruction of bicycles due to carelessness or abuse. The data of iiMedia Research showed, $30.8 \%$ of the respondents thought that random bicycle parking was the most prominent problem of bicycle sharing systems, while $18.2 \%$ thought that bicycle damage was common.

Shared bicycles need to be unlocked by a mobile phone scanner before use and consumers must pay the rental fees through mobile payment after use. The difference between sharing and traditional economies lies in fitting the model of supply and demand [1]. Bicycle sharing is also a special ecosystem that can be described by means of demand and supply interactions [6]. Fixed-pile shared-bicycle systems are composed of several bike stations that are located in different sites around the city, and each station has several slots where bicycles can be collected or returned [7]. In contrast with urban fixed-pile shared bicycles, a pile-free shared bicycle works by providing an integrated suite of services regarding shared bikes, such as searching, using, parking, and around-the-clock payment convenience from any location. In China, bicycle-sharing is both a model of economic development and an emerging business model. It is a type of sharing economy, with a business model that favors collaboration between the consumer and producer, primarily using technology, and a reciprocal relationship in which the objectives of each party are considered. Similar to car sharing services, bicycle sharing is also a traffic-sharing business model [8]. However, while it creates significant economic and social benefits, the bicycle-sharing market still faces several problems, including high rates of bicycle damage, disorderly parking, difficulty with the security deposits, and cut-throat competition. These issues are not conducive to the sustainable development of the bicycle-sharing market.

Air pollution and urban congestion are important reasons for the development of bicycle sharing systems in Chinese cities. There were 2311 days of serious pollution and 802 days of serious pollution according to the State of Ecological Environment Bulletin, which covers 338 cities in China and was issued by the Ministry of Ecology and Environment in 2017. PM2.5 was the main pollutant, accounting for $74.2 \%$ of the days when pollution was serious, or worse. According to the China Major Urban Traffic Analysis Report that was published by the Gaode Map, $61 \%$ of 361 cities in China were in slow traffic during rush hour in 2018. With the aggravation of environmental pollution and urban congestion, the demand on behalf of the government and users for the improvement of the travel environment is also intensifying. Bicycle sharing has been praised by society and encouraged by the government, as it is a green, convenient, and efficient travel mode. However, with the rapid development of the service, there are many problems regarding the sustainable use of shared bicycles. Therefore, this study focuses on the sustainable use intention of urban shared bicycles in China, including continual use intention, orderly parking intention, and care protection intention.

The existing research on shared transportation mainly focuses on the sustainable development of shared transportation and the environment, the policy and regulation of shared transportation, and the innovation that was provided by the business model behind shared transportation. A substantial part of the literature regarding sustainable shared transportation focuses on the sustainability of the bicycle-sharing industry. Most studies on the impact of shared transportation on sustainable environmental development assert that the use of shared transportation services plays a positive role in environmental protection and green development. Concerning the problems that arise from the rapid development of shared transportation services, relevant studies suggest that coordinated management 
by the market, government, and society should be implemented to promote the construction of a modern urban transportation system. The effect of the psychological and cultural factors of sustainability practices on consumers has also been studied, as well as the impact of the social norms and social context in which the sustainability practices take place $[9,10]$. The sustainable use of bicycle sharing requires an effective way of satisfying transportation demand [11] in order to improve the efficiency and service quality in this market [12,13]. To achieve this, the perceived functional, conditional, green, and social values dimensions of the bicycle-sharing business need to be investigated [14].

The theoretical contribution of this paper lies in its exploration of three broad types of factors that sustainably influence the intention to use urban bicycle sharing services. First, current research draws lessons from the technology acceptance model (TAM) or the theory of planned behavior (TPB) and it focuses on the characteristics of individual users, ignoring the usage conditions and the environment in which shared transportation occurs. This study considers the impact of the consumer's own disposition and characteristics, as well as the urban air quality on the sustainable use of shared bicycles to address this deficiency. Second, consumer innovation and behaviors responding to social norms are also considered, which allow us to incorporate features, such as business model innovation, green effects, health and environmental protection, and education into the analysis. Third, there are more studies on the use intention of shared transportation products than on standardized use, while there are only a few studies combining the perspectives of use intention and standardized use into the analysis of the sustainable use of shared bicycles. As a means of developing a more realistic model, we include a punishment policy to address disorderly parking and malicious damage, and measure the sustainability of the bicycle-sharing service through three dimensions: continual use intention (CUI), orderly parking intention (OPI), and care protection intention (CPI). These three measures of sustainability are more consistent with the realistic characteristics of shared transportation products.

The structure of the paper is as follows. Section 2 introduces the theoretical basis and develops our research model. Section 3 states the relevant hypotheses to be tested. Section 4 discusses our methodology and Section 5 describes the analysis and discusses the regression results. Section 6 concludes and discusses a number of implications that are derived from our findings.

\section{Theoretical Framework}

Bicycle-sharing services are an emerging mode of transportation that provide temporary rental access to publicly available bicycles. These programs have the potential to reduce car use in densely populated neighborhoods, thus reducing congestion. Additionally, these services promote healthy living and are environmentally friendly [3]. Shared bicycles operate under the time-sharing lease property model, namely, the same shared bicycle is used by different users at different times and the same user may use a different shared bicycle at different times. Due to the characteristics of time-sharing leasing and pile-free parking, shared bicycles not only provide convenience for users, but they may also encourage them to engage in inappropriate activities, such as randomly parking or even damaging the bicycles. Relevant studies posit that consumer behavior is important in the survival of this enterprise in a fiercely competitive market. Goodman and Irmak pay attention to the frequency of use, that is, how often a product is used or how many times it is used in a certain period [15]. For a shared bicycle, which has certain public goods attributes, not only the frequency of use, but also psychological factors, such as the intention of the user to park the shared bicycle properly or to care for it as a public good should be considered in the analysis.

It is a common method in many countries to formulate relevant laws and regulations on the use of public goods in the public interest, such as the bicycle helmet legislation in Finland, which went into effect on January 2003 and applies to cyclists of all ages [16]. In August 2017, the Ministry of Communications of the People's Republic of China issued the "Guiding Opinions on Encouraging and Regulating the Development of Internet Rental Bicycles". This document points out that, in the future development of the shared-bicycle services market, it is necessary to build a database tracking user behavior and establish a credit incentive and disciplining mechanism for users. However, the decision 
to adopt a punishment system may have an impact on of the intention to sustainably use the system. This study investigates which factors will affect the sustainable use intention of urban shared bicycles after the introduction of a punishment system. Firstly, as was the case with helmet legislation in Finland, the punishment system may reduce the bicycle use intention. Hence, shared bicycle continual use intention after the introduction of the punishment system is explicitly considered. Secondly, disorderly parking not only occupies public space resources on roads, but it also makes it difficult for other users to find shared bicycles. Therefore, this study analyzes the influencing factors of orderly parking intention. Thirdly, the destruction of shared bicycles makes it difficult for more users to use shared bicycles, resulting in the unsustainable use of shared bicycle. Therefore, this study analyzes care protection intention.

Social norms, which include both injunctive and descriptive norms, have an important role in shaping the behaviors of road users. Although the role of social norms for shared bicycles use has rarely been examined to date, there are several previous studies showing the significant role of social norms in predicting different transport behaviors. A survey study from Norway showed that increasing age, higher perceived benefits, both subjective and descriptive norms in favor of e-bikes, and familiarity with e-bikes were positively related to the intention to buy an e-bike, whereas perceived barriers that are related to usability and safety were negatively related to e-bike purchase intention [17]. Due to the use of shared bicycles being an outdoor activity on urban roads, the use of shared bicycles is also related to the air quality of the city. Environmental factors, such as poor weather and road conditions, were identified as the strongest barrier against e-bike use for both e-bike users and non-users [17]. Adverse weather conditions and a lack of safety were also found to be relevant discouraging factors [18]. Air pollution, which may discourage cycling, is an issue that needs to be addressed by transport policies, in order to enhance the engagement of the population in this mode of transportation.

On the basis of a theoretical review and a discussion of a number of practical problems, the theoretical framework of this paper is constructed (Figure 1), which analyzes the sustainable use intention of shared bicycles from three perspectives: use perception (perceived usefulness and perceived ease of use), consumer characteristics (consumer innovation and consumer social norm behavior), and urban characteristics (urban air quality).

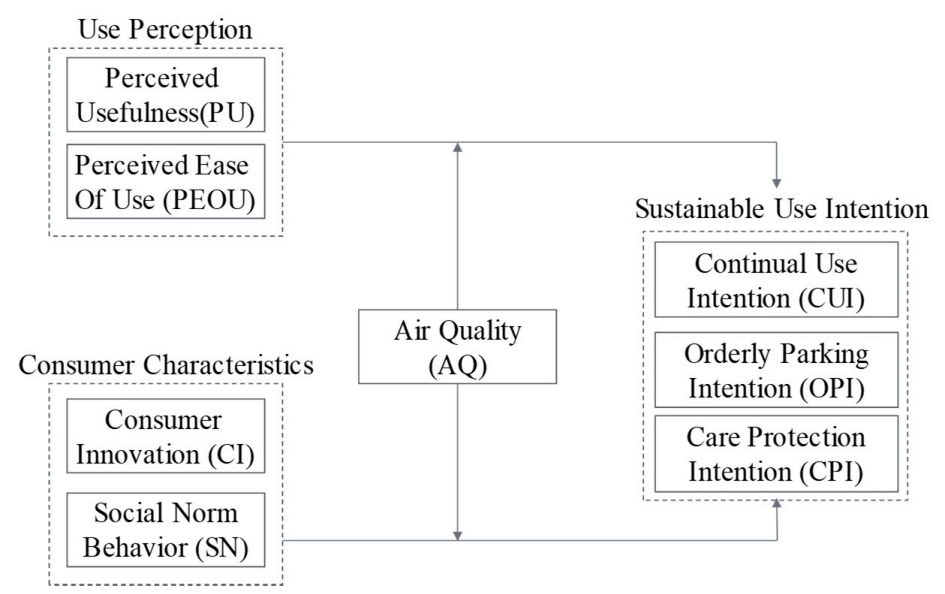

Figure 1. Theoretical Model.

\section{Hypothesis Development}

In 1989, Davis constructed a TAM of perceived usefulness (PU), perceived ease of use (PEOU), and other factors affecting usage behavior and the willingness to use a product [19]. The TAM has been continuously improved with changes in time background and research object, and the validity of these updated TAM models has also been verified [20]. Wang et al. find that perceived functions, perceived conditions, and perceived social values influence consumer willingness to use public bicycles [14]. Shared bicycle users have different perceptions of usefulness and ease of use regarding shared bicycles. 
When users think that shared bicycles are useful and easy to use, they may have a higher intention to use them. Therefore, we propose Hypotheses $\mathrm{H} 1$ and $\mathrm{H} 2$ :

Hypothesis 1. PU has an impact on the sustainable use intention of shared bicycles:

H1-1. PU has a positive impact on the CUI

H1-2. PU has a positive impact on the OPI

H1-3. PU has a positive impact on the CPI

Hypothesis 2. PEOU has an impact on the sustainable use intention of shared bicycles:

H2-1. PEOU has a positive impact on the CUI

H2-2. PEOU has a positive impact on the OPI

H2-3. PEOU has a positive impact on the CPI

Consumer innovation $(\mathrm{CI})$ refers to the ability of consumers to independently make innovative decisions without communicating with others [21]. CI is an important aspect of the individual characteristics of consumers, and highly innovative consumers are more likely to buy new products. The innovative characteristics of consumers reflect their individual psychological characteristics regarding their willingness to use new products. If consumers have strong innovation features, then they may have a greater willingness to accept new products than other consumers [22]. Shared transportation products have the characteristics of technological innovation and business model innovation. Highly innovative consumers may show more active sharing bicycle use behavior. Thus, we propose Hypothesis H3.

Hypothesis 3. CI has an impact on the sustainable use intention of shared bicycles:

H3-1. CI has a positive impact on the CUI

H3-2. CI has a positive impact on the OPI

H3-3. CI has a positive impact on the CPI

Broad social norms (SN) refer to the codes of conduct, rules and regulations, customs, moral laws, and values of the whole society, namely, of all social groups and their members. Relevant research on SN holds that individuals can internalize norms by absorbing and learning social norms, which thus implies that obeying social norms affects individual behavior. Individuals may also be subject to external pressures arising from social norms, which result in a behavior that follows social norms [23]. When choosing to cycle for commuting purposes over other transport options, individual factors with socio-psychological dimensions play an important role [24]. Shared transportation products have the attributes of public goods, and the use of public goods is influenced by social ethics. Hence, consumers with stronger social norms may show more sustainable use of shared bicycles. Therefore, we propose Hypothesis H4.

Hypothesis 4. SN has an impact on the sustainable use intention of shared bicycles:

H4-1. SN has a positive impact on the CUI

H4-2. SN has a positive impact on the OPI

H4-3. SN has a positive impact on the CPI

In the process of urbanization that has taken place in recent years in China, an increasing number of citizens use motor vehicles instead of bicycles as a means of travel, which has thus led to an increase in environmental pollution and a reduction in resident well-being. Expanding literature has explored the benefits of public bicycle share schemes from various perspectives, including user characteristics, journey time savings, convenience, health benefits, and reductions in motor vehicle use [25]. Serious environmental pollution will endanger the health of residents. For example, poor air 
quality will aggravate the condition of patients with respiratory diseases. Campbell et al. find that poor precipitation and air quality (AQ) have a strong negative impact on shared-bicycle demand [26]. Shared bicycles are used on outdoor urban roads, so AQ has an important impact on the use of shared bicycle. Therefore, Hypotheses $\mathrm{H} 5$ and $\mathrm{H} 6$ are proposed.

Hypothesis 5. AQ plays a moderating role in the impact of use perception on the sustainable use intention of shared bicycles:

H5-1. AQ plays a moderating role in the influence of use perception on the CUI

H5-2. AQ plays a moderating role in the impact of use perception on the OPI

H5-3. AQ plays a moderating role in the impact of use perception on the CPI

Hypothesis 6. AQ plays a moderating role in the impact of consumer characteristics on the sustainable use intention of shared bicycles:

H6-1. AQ plays a moderating role in the influence of consumer characteristics on the CUI

H6-2. AQ plays a moderating role in the impact of consumer characteristics on the OPI

H6-3. AQ plays a moderating role in the impact of consumer characteristics on the CPI

\section{Research Methodology}

\subsection{Measurement of the Variables}

This paper measures the research variables by compiling questionnaires that are based on relevant research. Although the questionnaire has been adapted from previous studies, the author it modified it due to the particularity of shared bicycles. To resolve potential problems with the questionnaire, two $\mathrm{PhD}$, three postgraduates, and three undergraduate students were invited to help address the academic and/or reading problems with the questionnaire. The answers for perceived ease of use, perceived usefulness, and consumer innovation were measured using five-point Likert scale, ranging from strongly disagree (1) to strongly agree (5).

\subsubsection{Interpreted Variables}

Sustainable shared-bicycle use intention is measured by means of the loss frame methodology. The loss frame methodology assumes that "if shared bicycles are used roughly, parked in a disorderly way, or damaged and violated by the user, the user will be punished. Continual Use Intention (CUI) is measured by means of the statement "I will continue to use shared bicycles in the future", Orderly parking intention (OPI) is measured by means of the statement "I will park my used shared bicycle in an orderly way", and Care Protection Intention (CPI) is measured by means of the statement "I will care and protect shared bicycles".

\subsubsection{Explanatory and Regulatory Variables}

Perceived Usefulness (PU) and Perceived ease of use (PEOU) refer to Venkatesh et al. [27], combining the current bicycle sharing situation in China to compile questionnaires. PEOU is measured by four Likert five-point scale items: "Shared bicycles are easy to lock and park after use", "Areas suitable for parking shared bicycles are easy to find after use", "Parking shared bicycles neatly and in an orderly manner after use", and "When I need to, I can find nearby shared bicycles". PU is measured by four Likert five-point scale items: "Using shared bicycle can make my trip more convenient", "Using shared bicycle can help me avoid traffic congestion", "Using shared bicycle can achieve the desired convenience effect", and "Living in the city, I believe that it is very wise to open shared bicycle account and use shared bicycle".

Consumer Innovation (CI), as introduced by Goldsmith and Hofacker (1999) [28], is measured by three Likert five-point scale items: "I think the new way of life and work is a progress compared with 
the past", "I am willing to accept the challenge of new things, even if it takes a lot of time and energy", and "I am more willing to accept new ideas and things". Social Norms Behavior (SN) measures the percentage of users who have not obeyed traffic lights and crossed the street through red lights during walking and cycling.

Urban Air Quality (AQ) is measured by a one-degree item from “Urban Air Quality in Your Living Area".

\subsubsection{Other Variables}

Gender (Gen), age (Age), and education (Edu) are selected as the control variables to further verify whether the degree of user demand for shared bicycles is affected by demographic factors. In addition, the presence of the most popular shared-bicycle companies (i.e., Mobike bicycle, OFO bicycle, Hellobike bicycle) and the purpose of using the shared bicycle (i.e., "only using shared bicycle to destination" and "using shared bicycle to destination in addition to metro/bus") were also investigated.

\subsection{Sample Selection}

A survey was conducted to study domestic users who use shared bicycles. The survey was conducted in September 2018. The questionnaires were distributed on an online platform in China, sojump.com. Sojump.com is the largest online survey website in China, with a claimed 1.67 billion returned questionnaires and participation from over $90 \%$ of Chinese universities and research institutions. A total of 702 questionnaires were sent out and 532 questionnaires were collected. Among them, 14 questionnaires with short response times were considered to be invalid, and 518 questionnaires were deemed as valid. Table 1 describes the sample. Among the most used shared bicycles, $42.7 \%$ are OFO bicycles, $31.5 \%$ are Mobike bicycles, and $24.5 \%$ are Hellobike bicycles. In terms of purpose when using a shared-bicycle service, $48.6 \%$ of the users declare that they use the service to go directly to their destination, while $51.4 \%$ use the service to go to their destination in addition to using public transportation (metro/bus). Among the scenarios in which shared bicycles were the most used, $34.3 \%$ were for shopping and $51 \%$ were for commuting. The sample characteristics are similar to those that were identified by other papers or reports. Among shared bicycle users, there are slightly more males than females [29], and users with undergraduate qualifications or above accounted for 76.4\% (BigData-Research.org).

Table 1. Sample Description.

\begin{tabular}{cccc}
\hline Feature & Values & Frequency & Percentage \\
\hline \multirow{2}{*}{ Gender } & Male & 202 & 39.0 \\
& Female & 316 & 61.0 \\
\hline \multirow{2}{*}{ Age } & $\leq 25$ & 172 & 33.2 \\
& $26 \sim 30$ & 147 & 28.4 \\
& $31 \sim 40$ & 164 & 31.7 \\
Education & $\geq 41$ & 35 & 6.8 \\
level & Junior college and below & 76 & 14.6 \\
& Undergraduate & 396 & 76.4 \\
Income per & Master and above & 46 & 8.9 \\
year & $\leq 60$ thousand & 140 & 27.0 \\
& $60 \sim 120$ thousand & 249 & 48.1 \\
& $120 \sim 240$ thousand & 111 & 21.4 \\
& $\geq 240$ thousand & 18 & 3.5 \\
\hline \multirow{2}{*}{ Living city } & County and below & 26 & 5.0 \\
& Second-tier city or provincial capital & 204 & 19.3 \\
& First-tier city & 188 & 39.4 \\
\hline
\end{tabular}




\subsection{Model Fit}

The model was fit by means of SPSS22 and AMOS22 software (Table 2). The KMO value, Cronbach's $\alpha$ value, and variable factor loading were all greater than the recommended value of 0.7 , and the AVE of the variables were all greater than 0.5, which implies that the measurement items had good reliability and the measurement model had good convergence validity. The AVE square root of each variable is larger than the correlation coefficient between the factors, so the measurement model has good discriminatory validity.

Table 2. Summary of Reliability and Validity.

\begin{tabular}{|c|c|c|c|c|}
\hline Variables & & Measure & $\begin{array}{l}\text { Factor } \\
\text { Loading }\end{array}$ & $\begin{array}{l}\text { KMO/Cronbach's } \\
\text { \&/AVE }\end{array}$ \\
\hline \multirow{4}{*}{$\begin{array}{l}\text { Perceived } \\
\text { ease of use } \\
\text { (PEOU) [27] }\end{array}$} & PE1 & $\begin{array}{l}\text { Shared bicycles are easy to lock and park } \\
\text { after use }\end{array}$ & 0.712 & \multirow{4}{*}{$0.705 / 0.720 / 0.615$} \\
\hline & PE2 & $\begin{array}{l}\text { Areas suitable for parking shared bicycles are } \\
\text { easy to find after use }\end{array}$ & 0.741 & \\
\hline & PE3 & $\begin{array}{l}\text { Parking shared bicycles neatly and orderly } \\
\text { after use }\end{array}$ & 0.703 & \\
\hline & PE4 & $\begin{array}{l}\text { When I need to, I can find nearby shared } \\
\text { bicycles }\end{array}$ & 0.774 & \\
\hline \multirow{4}{*}{$\begin{array}{c}\text { Perceived } \\
\text { Usefulness } \\
\text { (PU) [27] }\end{array}$} & PU1 & $\begin{array}{l}\text { Using shared bicycle can make my trip more } \\
\text { convenient }\end{array}$ & 0.719 & \multirow{4}{*}{$0.703 / 0.709 / 0.608$} \\
\hline & PU2 & $\begin{array}{l}\text { Using shared bicycle can help me avoid } \\
\text { traffic congestion }\end{array}$ & 0.713 & \\
\hline & PU3 & $\begin{array}{l}\text { Using shared bicycle can achieve the desired } \\
\text { convenience effect }\end{array}$ & 0.719 & \\
\hline & PU4 & $\begin{array}{l}\text { I believe that it is very wise to open shared } \\
\text { bicycle account and use shared bicycle }\end{array}$ & 0.764 & \\
\hline \multirow{3}{*}{$\begin{array}{l}\text { Consumer } \\
\text { Innovation } \\
\text { (CI) [28] }\end{array}$} & CI1 & $\begin{array}{l}\text { I think the new way of life and work is a } \\
\text { progress compared with the past }\end{array}$ & 0.749 & \multirow{3}{*}{$0.787 / 0.716 / 0.513$} \\
\hline & $\mathrm{CI} 2$ & $\begin{array}{l}\text { I am willing to accept the challenge of new } \\
\text { things, even if it takes a lot of time and energy }\end{array}$ & 0.708 & \\
\hline & $\mathrm{CI} 3$ & $\begin{array}{l}\text { I am more willing to accept new ideas and } \\
\text { things }\end{array}$ & 0.786 & \\
\hline
\end{tabular}

\subsection{Correlation Analysis}

The data are standardized to eliminate the influence of the number of dimensions and the varying degree of the variables. Table 3 shows the Pearson correlation coefficients of the main variables after standardization. The correlation of variables reflects the following main characteristics. First, the CUI is significantly correlated with age (Age), educational level (Edu), perceived usefulness (PU), perceived ease of use (PEOU), CI, SN, and AQ. Second, OPI is significantly correlated with Gen, PU, PEOU, CI, and SN. Third, CPI is significantly correlated with Gen, PU, PEOU, CI, and SN. 
Table 3. Correlation Analysis.

\begin{tabular}{|c|c|c|c|c|c|c|c|c|c|c|c|}
\hline & 1 & 2 & 3 & 4 & 5 & 6 & 7 & 8 & 9 & 10 & 11 \\
\hline 1 Gen & 1 & & & & & & & & & & \\
\hline 2 Age & $-0.139^{* * *}$ & 1 & & & & & & & & & \\
\hline 3 Edu & -0.007 & $0.099 * *$ & 1 & & & & & & & & \\
\hline $4 \mathrm{PU}$ & $0.104^{* *}$ & 0.076 & $0.105^{* *}$ & 1 & & & & & & & \\
\hline 5 PEOU & 0.006 & $0.224 * * *$ & 0.083 & $0.317^{* * *}$ & 1 & & & & & & \\
\hline $6 \mathrm{CI}$ & $0.099 * *$ & 0.037 & $0.085^{*}$ & $0.318^{* * *}$ & $0.227^{* * *}$ & 1 & & & & & \\
\hline $7 \mathrm{SN}$ & -0.029 & 0.033 & 0.058 & $0.146^{* * *}$ & $0.112 * *$ & 0.052 & 1 & & & & \\
\hline $8 \mathrm{AC}$ & $-0.087^{* *}$ & 0.068 & $0.090^{* *}$ & -0.004 & $-0.128^{* * *}$ & -0.011 & -0.067 & 1 & & & \\
\hline 9 CUI & -0.010 & $0.118^{* *}$ & 0.111 * & $0.204^{* *}$ & $0.318^{* *}$ & $0.220^{* *}$ & $0.117^{* *}$ & -0.027 & 1 & & \\
\hline $10 \mathrm{OPI}$ & $0.110^{* *}$ & -0.002 & 0.048 & $0.290^{* * *}$ & $0.167^{* * *}$ & $0.205^{* * *}$ & $0.109^{* *}$ & 0.032 & $0.243^{* * *}$ & 1 & \\
\hline $11 \mathrm{CPI}$ & $0.082 *$ & 0.041 & 0.009 & $0.157^{* * *}$ & $0.185^{* * *}$ & $0.204^{* * *}$ & 0.039 & 0.014 & $0.312 * * *$ & $0.289 * * *$ & 1 \\
\hline
\end{tabular}

\section{Analysis}

\subsection{The Influence of Bicycle-Sharing Using Perception}

Nine models were constructed in order to test the effects of PU and PEOU on the CUI, OPI, and CPI of shared bicycles, and the mediating role of AQ (Table 4). In model 1, the regression coefficients of age and education level are significant, which indicates that the older and more educated users will continue to use shared bicycles when a punishment policy of disorderly parking and damage is introduced. In model 2, consumer PU and PEOU have a significant positive impact on the continued intention to use shared bicycles. Among these relationships, PEOU has a higher impact. Therefore, hypotheses H1-1 and H2-1 are confirmed. In model 4, the regression coefficient of gender is significant, indicating that, when a policy to punish disorderly parking and damaging behavior is introduced, the female users have a higher inclination to park the shared bicycle in an orderly way. In model 5, PU and PEOU have a significant positive impact on the OPI of shared bicycles. PU has a higher impact, while PEOU has a relatively low impact (significant only at the 0.1 level). Hypotheses H1-2 and $\mathrm{H} 2-2$ are also confirmed in this case. In model 7, the regression coefficient of gender is significant, which indicates that, when the punishment policy for disorderly parking and damaging behavior is introduced, female users are more likely to care and protect shared bicycles. In model 8, PU and PEOU have a significant positive impact on care protection intention; PEOU has a higher impact. Hypothesis H1-3 and H2-3 are thus confirmed.

Table 4. Bicycle-sharing Using Perception Analysis.

\begin{tabular}{cccccccccc}
\hline & \multicolumn{3}{c}{ Continual Use Intention } & \multicolumn{3}{c}{ Orderly Parking Intention } & \multicolumn{3}{c}{ Care Protection Intention } \\
\hline Variable & $\mathrm{M} 1$ & $\mathrm{M} 2$ & $\mathrm{M} 3$ & $\mathrm{M} 4$ & $\mathrm{M} 5$ & $\mathrm{M} 6$ & $\mathrm{M} 7$ & $\mathrm{M} 8$ & $\mathrm{M} 9$ \\
\hline Gen & 0.006 & & & $0.111^{* *}$ & $0.083^{*}$ & $0.083^{*}$ & $0.089^{* * *}$ & 0.070 & 0.066 \\
Age & $0.109^{* *}$ & 0.042 & 0.055 & 0.009 & & & 0.053 & \\
Edu & $0.101^{* *}$ & $0.074^{*}$ & $0.075^{*}$ & 0.048 & & & 0.005 & \\
\hline PU & & $0.108^{* *}$ & & & $0.255^{* * *}$ & & & $0.102^{* * *}$ \\
PEOU & & $0.269^{* * *}$ & & & $0.086^{*}$ & & & $0.152^{* * *}$ \\
AQ $\times$ PU & & & $0.119^{* * *}$ & & & $0.242^{* * *}$ & & & $0.121^{* * *}$ \\
AQ $\times$ PEOU & & & $0.264^{* * *}$ & & & $0.080^{*}$ & & & $0.133^{* * *}$ \\
\hline F & $4.207^{* * *}$ & $17.599^{* * *}$ & $17.834^{* * *}$ & $2.515^{*}$ & $18.480^{* * *}$ & $16.358^{* * *}$ & 1.637 & $9.002^{* * *}$ & $8.615^{* * *}$ \\
$\mathrm{R}^{2}$ & 0.024 & 0.121 & 0.122 & 0.014 & 0.097 & 0.087 & 0.009 & 0.050 & 0.048 \\
$\Delta \mathrm{R}^{2}$ & 0.018 & 0.114 & 0.115 & 0.009 & 0.092 & 0.082 & 0.004 & 0.044 & 0.042 \\
\hline
\end{tabular}

In model 3, the multiplier coefficients of $A Q$ and PU or PEOU are both positive and significant. Therefore, AQ plays a positive mediating role in the relationship between PE and CUI and between PEOU and CUI. In model 6, the multiplier coefficients of AQ and PU or PEOU are both positive and significant; therefore, in the relationship between PU and OPI and between PEOU and OPI, urban AQ plays a positive mediating role. In model 9, the multiplier coefficients of $A Q$ ) and PU or PEOU are both positive and significant; therefore, $\mathrm{AQ}$ also plays a positive mediating role in the relationship between 
PU and CPI and between PEOU and CPI. Hence, model 3, model 6, and model 9 confirm Hypothesis $\mathrm{H} 5$, and we conclude that $\mathrm{AQ}$ indeed plays a regulatory role in the impact of PU and PEOU on the three dimensions of the sustainable use of shared bicycles considered in this study (CUI, OPI, and CPI).

\subsection{The Influence of Consumer Characteristics}

Six models were constructedin order to examine the impact of consumer innovation and social norm behavior on the CUI, OPI, and CPI toward shared bicycles, and the regulatory role of AQ in these relationships (Table 5). In model 10, the $\mathrm{CI}$ and SN behaviors have significantly positive effects on the intention to continue using shared bicycles, with $\mathrm{CI}$ having a higher impact on CUI than SN behaviors. Hypothesis H3-1 and H4-1 are thus confirmed. In model 12, CI and SN behavior have significantly positive effects on the OPI of shared bicycles, with CI having the higher impact. Therefore, Hypothesis H3-2 and H4-2 are confirmed. In model 14, CI has a significantly positive impact on the CPI of shared bicycles, while SN behavior has no significant impact on the CPI, thus confirming Hypothesis H3-3.

Table 5. Consumer Characteristics Analysis.

\begin{tabular}{|c|c|c|c|c|c|c|}
\hline \multirow[b]{2}{*}{ Variable } & \multicolumn{2}{|c|}{ Continual Use Intention } & \multicolumn{2}{|c|}{ Orderly Parking Intention } & \multicolumn{2}{|c|}{ Care Protection Intention } \\
\hline & M 10 & M 11 & M 12 & M 13 & M 14 & M 15 \\
\hline Gen & & & $0.094^{* *}$ & $0.096^{* *}$ & 0.063 & 0.063 \\
\hline Age & $0.099 * *$ & $0.100 * *$ & & & & \\
\hline Edu & $0.078 *$ & $0.082 *$ & & & & \\
\hline $\mathrm{CI}$ & $0.205^{* * *}$ & & $0.191^{* * *}$ & & $0.196^{* * *}$ & \\
\hline SN & $0.098 * *$ & & $0.102 * *$ & & 0.030 & \\
\hline $\mathrm{AQ} \times \mathrm{CI}$ & & $0.197^{* * *}$ & & $0.179^{* * *}$ & & $0.190^{* * *}$ \\
\hline $\mathrm{AQ} \times \mathrm{SN}$ & & 0.045 & & 0.084 * & & 0.033 \\
\hline $\mathrm{F}$ & $10.708^{* * *}$ & $8.896^{* * *}$ & $11.066^{* * *}$ & $9.388^{* * *}$ & $8.331^{* * *}$ & $7.846^{* * *}$ \\
\hline $\mathrm{R}^{2}$ & 0.077 & 0.065 & 0.061 & 0.052 & 0.046 & 0.044 \\
\hline$\Delta \mathrm{R}^{2}$ & 0.070 & 0.058 & 0.055 & 0.046 & 0.041 & 0.038 \\
\hline
\end{tabular}

In model 11, the multiplier coefficients of $A Q$ and $C I$ are positive and significant, while the multiplier coefficients of $\mathrm{AQ}$ and $\mathrm{SN}$ are not. This shows that urban air quality plays a positive mediating role in the relationship between $\mathrm{CI}$ and the intention to continue using shared bicycles, while it has no significant role in the relationship between $\mathrm{SN}$ behavior and the intention to continue using the service. In model 13, the multiplier coefficients of $A Q$ and $C I$ and the multiplier coefficients of $A Q$ and $\mathrm{SN}$ are positive and significant, but the multiplier coefficients of AQ and SN are relatively low (and only significant at the 0.1 level). Therefore, in the relationship between CI and OPI, as well as in the relationship between $\mathrm{SN}$ and OPI, AQ plays a positive mediating role. In model 15, the multiplier coefficient of $\mathrm{AQ}$ and $\mathrm{CI}$ is positive and significant, which indicates that $\mathrm{AQ}$ plays a positive regulatory role in the relationship between CI and CPI. Models 11, 13, and 15 confirm Hypothesis H6-2, while H6-1 and H6-3 are not confirmed.

\section{Conclusions and Suggestions}

This study builds research models and hypotheses that are based on shared-bicycle use perception and user characteristics by collecting data through questionnaires and studying the shared-bicycle sustainable use intention through statistical analysis. This paper assumes a loss frame setup corresponding to the notion that "if shared bicycles are used roughly, parked in a disorderly way, damaged and violated by user, the user will be punished". In order to provide theoretical support for managers of bicycle-sharing services, this study explores the factors that influence three dimensions: continual use intention (CUI), orderly parking intention (OPI), and care protection intention (CPI) of shared bicycles in loss frame. The main findings are as follows: First, perceived usefulness, perceived ease of use, and consumer innovation have significant positive effects on the CUI and OPI of shared 
bicycles. Urban air quality plays a regulatory role in these relations. Second, perceived usefulness, perceived ease of use, and consumer innovation have a significant positive impact on the CPI of shared bicycles, while social normative behavior has no significant impact. Urban air quality does not play a regulatory role in the relationship between social normative behavior and CUI and OPI. Third, when the punishment policy of disorderly parking and damage is promulgated, the regression coefficient of age and education level to the CUI of shared bicycles is significant, which indicates that the older and the high-educated users are more likely to continue the use of shared bicycles. The regression coefficient of gender to OPI and CPI is significant, which indicates that the female users have high OPI and CPI.

Shared transportation is related to economic growth, social well-being, and the happiness of a city's residents. For shared-bicycle operators, improving CUI is an important business objective. This study finds that the introduction of a shared-bicycle governance system in the future can provide theoretical support for shared-bicycle operators and regulators. We can use the demonstration and supervision function of those users who are highly innovative and have high social norms in order to improve users' CUI and OPI, thus influencing other users to care and protect bicycles in the process of using shared bicycles. Moreover, enhancing the usefulness and ease of use of shared bicycles is another way of enhancing user CUI, OPI, and CPI of shared bicycles. Consumers themselves, usage situations, and institutional rules may also influence the sustainable use of shared bicycles. Improving urban air quality can enhance users' CUI, OPI, and CPI.

Nowadays, self-service bike sharing services are flourishing all over the world. Regardless of whether the shared bicycle service has fixed or non-fixed piles, the exploitation of such transport systems entails various issues, and one of them is to assure people that they will be able to find a bike or to park it at each station throughout the day. Therefore, a regulation system is necessary in maintaining a prefixed optimal number of bikes at each area to best meet demand. In addition, a better scheduling system is needed to adjust the number of shared bicycles in different locations in order to avoid the accumulation of shared bicycles and disorderly parking.

\section{Discussion}

An important finding of the study is that adding variables to the TAM can increase the understanding and explanation of the sustainable use intention of shared bicycles. The results of this study suggest that perceived usefulness, perceived ease of use, consumer innovation, and consumer social norm behavior helped to predict the sustainable use intention.

The finding of this study regarding perceived usefulness is consistent with existing evidence that functional value plays an important role for cycling behavior [14]. Functional Value has been defined as the perceived utility that is acquired from specific attributes of a product or service. Users' perceived ease of use should also be taken into account, as shared bicycles are a relatively new transport option, which is searched for and locked by mobile applications. This study applies the technology acceptance model for reference and improves upon it. The finding from social norm behaviour in this study is similar to the existing evidence that social norms are positively related with the intention to adopt an e-bike [17]. In addition, previous studies suggest that poor air quality strongly negatively impacted demand for bikesharing [25]. This study further explores the positive regulatory role of air quality, that is urban air quality plays a regulatory role between use perception and sustainable use intention for shared bicycles.

However, what is important in this study is that the use intention is differently defined from most previous studies. This study focuses on the use intention after the introduction of the punishment system, which will be introduced in the future. In addition, the sustainable use intention that is proposed in this study not only includes whether to continue to use, but it also considers the particularity of sharing bicycles and other public goods. In other words, the intention to park in an orderly manner and to cherish protection is considered. Therefore, this study further expands the research on the product use intention in the context of shared bicycles, and it provides a more systematic model for 
the research on shared bicycles, shared electric vehicles, shared cars, and other time-sharing leasing public goods.

\section{Study Limitations}

Although new technology and GPS systems have provided the technical foundation for the implementation of a punishment policy in future, the downside of this development is that, for users, there may be two reasons that lead to a lower use of the shared bicycles. First, users may be punished for inappropriate behaviors, such as damage or incorrect parking. Second, the user may be worried about being wrongly punished by other users' inappropriate behaviors. Both reasons may lead individuals to reduce their use intention in order to avoid potential punishments. However, this study was unable to distinguish which reason (or potential other reasons) has/have greater impact on sustainable use intention of shared bicycles.

It is recommended that further research be conducted on how to improve the accuracy of the punishment policy and how to reduce the perceived risk of bicycle sharing users' uncertainties in the implementation of the punishment policy. In addition, when the bicycle sharing policy is implemented in the future, the applicability of this research model and the rationality of the research conclusions can be further tested under the new situation. Finally, we suggest that a comparative study of metropolitan and medium-sized cities would also be an important development to investigate whether the same model constructs can be identified in different conditions.

Author Contributions: P.S. performed the theory analysis and improved the empirical analysis and writing. J.L. improved the writing and conclusions.

Funding: The research for this paper was supported by the Ministry of Education, Humanities and Social Sciences Foundation of China (No. 18YJC630139), and the Shaanxi Natural Science Foundation (No. 2018JQ7001).

Conflicts of Interest: The authors declare no conflict of interest.

\section{References}

1. Chen, X.; Qu, Q.; Chen, M.-H.; Fang, S.; Cheng, Y. The Sustainable Existence of China's Bicycle-Sharing Market: To Oversupply or to Disappear. Sustainability 2018, 10, 4214. [CrossRef]

2. George, D.K.; Xia, C.H. Fleet-sizing and service availability for a vehicle rental system via closed queueing networks. Eur. J. Oper. Res. 2011, 211, 198-207. [CrossRef]

3. Faghih-Imani, A.; Hampshire, R.; Marla, L.; Eluru, N. An empirical analysis of bike sharing usage and rebalancing: Evidence from Barcelona and Seville. Transp. Res. Part A Policy Pract. 2017, 97, $177-191$. [CrossRef]

4. Hamari, J.; Sjöklint, M.; Ukkonen, A. The sharing economy: Why people participate in collaborative consumption. J. Assoc. Inf. Sci. Technol. 2016, 67, 2047-2059. [CrossRef]

5. Belk, R. You are what you can access: Sharing and collaborative consumption online. J. Bus. Res. 2014, 67, 1595-1600. [CrossRef]

6. Wei, H.; Fan, W.; Wang, X.; Lu, N.; Dong, X.; Zhao, Y.; Ya, X.; Zhao, Y. Integrating supply and social demand in ecosystem services assessment: A review. Ecosyst. Serv. 2017, 25, 15-27. [CrossRef]

7. Dell Amico, M.; Iori, M.; Novellani, S.; Stützle, T. A destroy and repair algorithm for the Bike sharing Rebalancing Problem. Comput. Oper. Res. 2016, 71, 149-162. [CrossRef]

8. Barth, M.; Shaheen, S.A. Shared-Use Vehicle Systems: Framework for Classifying Carsharing, Station Cars, and Combined Approaches. Transp. Res. Rec. 2002, 1791, 105-112. [CrossRef]

9. Yin, J.; Qian, L.; Singhapakdi, A. Sharing Sustainability: How Values and Ethics Matter in Consumers' Adoption of Public Bicycle-Sharing Scheme. J. Bus. Ethics 2018, 149, 313-332. [CrossRef]

10. Mugion, R.G.; Toni, M.; Raharjo, H.; Di Pietro, L.; Sebathu, S.P. Does the service quality of urban public transport enhance sustainable mobility? J. Clean. Prod. 2018, 174, 1566-1587. [CrossRef]

11. Williams, A. Product-service systems in the automotive industry: The case of micro-factory retailing. J. Clean. Prod. 2006, 14, 172-184. [CrossRef] 
12. Bordagaray, M.; Ibeas, A.; Dell Olio, L. Modeling User Perception of Public Bicycle Services. Procedia Soc. Behav. Sci. 2012, 54, 1308-1316. [CrossRef]

13. Kaplan, S.; Wrzesinska, D.K.; Prato, C.G. The role of human needs in the intention to use conventional and electric bicycle sharing in a driving-oriented country. Transp. Policy 2018, 71, 138-146. [CrossRef]

14. Wang, Y.; Douglas, M.A.; Hazen, B.T.; Dresner, M. Be green and clearly be seen: How consumer values and attitudes affect adoption of bicycle sharing. Transp. Res. Part F Traffic Psychol. Behav. 2018, 58, 730-742. [CrossRef]

15. Goodman, J.K.; Irmak, C. Having Versus Consuming: Failure to Estimate Usage Frequency Makes Consumers Prefer Multifeature Products. J. Mark. Res. 2013, 50, 44-54. [CrossRef]

16. Radun, I.; Olivier, J. Bicycle helmet law does not deter cyclists in Finland. Transp. Res. Part F Traffic Psychol. Behav. 2018, 58, 1087-1090. [CrossRef]

17. Simsekoglu, Ö.; Klöckner, C. Factors related to the intention to buy an e-bike: A survey study from Norway. Transp. Res. Part F Traffic Psychol. Behav. 2019, 60, 573-581. [CrossRef]

18. Useche, S.A.; Montoro, L.; Sanmartin, J.; Alonso, F. Healthy but risky: A descriptive study on cyclists' encouraging and discouraging factors for using bicycles, habits and safety outcomes. Transp. Res. Part F Traffic Psychol. Behav. 2019, 62, 587-598. [CrossRef]

19. Davis, F.D.; Bagozzi, R.P.; Warshaw, P.R. User Acceptance of Computer Technology: A Comparison of Two Theoretical Models. Manag. Sci. 1989, 35, 982-1003. [CrossRef]

20. Adams, D.A.; Nelson, R.R.; Todd, P.A. Perceived Usefulness, Ease of Use, and Usage of Information Technology: A Replication. MIS Quart. 1992, 16, 227-247. [CrossRef]

21. Midgley, D.F.; Dowling, G.R. Innovativeness: The Concept and Its Measurement. J. Consum. Res. 1978, 4, 229-242. [CrossRef]

22. Hong, J.; Lin, P.; Hsieh, P. The effect of consumer innovativeness on perceived value and continuance intention to use smartwatch. Comput. Hum. Behav. 2017, 67, 264-272. [CrossRef]

23. McAdams, R.H. The Origin, Development, and Regulation of Norms. Mich. Law Rev. 1997, 96, $338-433$. [CrossRef]

24. Bullock, C.; Brereton, F.; Bailey, S. The economic contribution of public bike-share to the sustainability and efficient functioning of cities. Sustain. Cities Soc. 2017, 28, 76-87. [CrossRef]

25. Campbell, A.A.; Cherry, C.R.; Ryerson, M.S.; Yang, X. Factors influencing the choice of shared bicycles and shared electric bikes in Beijing. Transp. Res. Part C Emerg. Technol. 2016, 67, 399-414. [CrossRef]

26. Venkatesh, V.; Morris, M.G.; Davis, G.B.; Davis, F.D. User Acceptance of Information Technology: Toward a Unified View. MIS Quart. 2003, 27, 425-478. [CrossRef]

27. Cepeda Zorrilla, M.; Hodgson, F.; Jopson, A. Exploring the influence of attitudes, social comparison and image and prestige among non-cyclists to predict intention to cycle in Mexico City. Transp. Res. Part F Traffic Psychol. Behav. 2019, 60, 327-342. [CrossRef]

28. Goldsmith, R.E.; Hofacker, C.F. Measuring consumer innovativeness. J. Acad. Mark. Sci. 1991, 19, $209-221$. [CrossRef]

29. Wu, Y.; Xian, Z.; Qiu, J.; Chen, Y.; Yang, Y. Investigation and Analysis of the Current Situation of Shared Bike Users. Manag. Observ. 2018, 23, 67-71. (In Chinese)

(C) 2019 by the authors. Licensee MDPI, Basel, Switzerland. This article is an open access article distributed under the terms and conditions of the Creative Commons Attribution (CC BY) license (http://creativecommons.org/licenses/by/4.0/). 